\title{
Antimicrobial and Mechanical Effects of Zeolite Use in Dental Materials: A Systematic Review
}

\section{Antimikrobni i mehanički učinci upotrebe zeolita u dentalnim materijalima: sistematizirani pregledni rad}

\author{
${ }^{1}$ Department of Biology, School of Arts and Sciences, University of Pennsylvania, Philadelphia, Pennsylvania \\ Odjel za biologiju Škole za umjetnost i znanost Sveučilišta Pensylvania, Philadelphia, Pennsylvania \\ 2 Department of Preventive and Restorative Sciences, School of Dental Medicine, University of Pennsylvania, Philadelphia, Pennsylvania \\ Odjel za preventivnu i restaurativnu stomatologiju Stomatološkog fakulteta Sveučilišta Pennsylvania, Philadelphia, Pennsylvania \\ 3 Faculty of Medicine, Juraj Dobrila University of Pula, Pula, Croatia \\ Medicinski fakultet Sveučilišta Jurja Dobrile u Puli, Hrvatska
}

Abstract

Objective: Ion-incorporated zeolite is a widely used antimicrobial material studied for various dental applications. At present, there is no other systematic review that evaluates the effectiveness of zeolite in all dental materials. The purpose of this study was to review all available literature that analyzed the antimicrobial effects and/or mechanical properties of zeolite as a restorative material in dentistry. Material and methods: Following PRISMA guidelines, an exhaustive search of PubMed, Ovid Medline, Scopus, Embase, and the Dentistry \& Oral Sciences Source was conducted. No language or time restrictions were used and the study was conducted from June 1, 2020 to August 17, 2020. Only full text articles were selected that pertained to the usage of zeolite in dental materials including composite resin, bonding agents, cements, restorative root material, cavity base material, prosthesis, implants, and endodontics. Results: At the beginning of the study, 1534 studies were identified, of which 687 duplicate records were excluded. After screening for the title, abstract, and full texts, 35 articles remained and were included in the qualitative synthesis. An Inter-Rater Reliability (IRR) test, which included a percent user agreement and reliability percent, was conducted for each of the 35 articles chosen. Conclusion: Although ion-incorporated zeolite may enhance the antimicrobial properties of dental materials, the mechanical properties of some materials, such as MTA and acrylic resin, may be compromised. Therefore, since the decrease in mechanical properties depends on zeolite concentration in the restorative material, it is generally recommended to add $0.2-2 \%$ zeolite by weight.
Received: November 8, 2020

Accepted: February 1, 2021

Address for correspondence Fusun Ozer, DMD, PhD

University of Pennsylvania

School of Dental Medicine

Department of Preventive and

Restorative Sciences

240 S 40th Street, Schattner Building,

Philadelphia, PA 19106, USA

Phone: +1 2155733751

ozerf@upenn.edu

MeSH terms: Zeolites; Mechanical Phenomena; Anti-Infective Agents; Dental Materials

Author keywords: zeolite, dental material, antimicrobial, mechanical property, systematic review

\section{Introduction}

Zeolite, an aluminosilicate with a tetrahedral crystalline structure, has extensive applications ranging from ecology to dentistry $(1,2)$. Zeolite is particularly useful to these fields due to its unique porous structure, which creates negatively charged channels and cavities that can hold cations, hydroxyl groups, and water molecules (1). Recently, zeolite's ability to uptake and release ions, combined with its superior biocompatibility and long-lasting effects, has increased the attention on the compound in dental research (2).

In addition to solely adding zeolite to materials, many studies in dentistry have attempted to combine zeolite with inorganic antimicrobial ions, such as silver and zinc, for controlled release (2). Particularly, most of the studies focus on silver-incorporated zeolite (AgZ) since zeolite has a strong affinity for silver ions. In addition, silver ions are less toxic to
Uvod

Zeolit, alumosilikat $s$ tetraedrskom kristalnom strukturom ima široku primjenu - od ekologije do stomatologije (1, 2). Zeolit je posebno koristan za ta područja zbog jedinstvene porozne strukture koja stvara negativno nabijene kanale i šupljine u kojima se mogu naći kationi, hidroksilne skupine i molekule vode (1). Odnedavno se, zbog svojstva zeolita da apsorbira i oslobađa ione, u kombinaciji s njegovom odličnom biokompatibilnošću i dugotrajnim učincima, povećalo zanimanje za taj spoj u stomatološkim istraživanjima (2).

Uz dodavanje samo zeolita u materijale, u mnogim ga se istraživanjima pokušalo kombinirati $s$ anorganskim antimikrobnim ionima poput srebra i cinka za kontrolirano otpuštanje (2). Autori većine istraživanja posebno se usredotočuju na zeolit sa srebrom (AgZ) jer zeolit ima jak afinitet prema ionima srebra. Uz to, ioni srebra manje su toksični za ljudska 
human tissues than other metallic ions, such as copper and mercury $(3,4)$. When cations become available in the surrounding oral environment, zeolite exchanges the environmental cation with its embedded silver ions. This, in turn, only occurs with the presence of moisture and until the silver concentration meets the local equilibrium value. Therefore, $\mathrm{AgZ}$ may offer targeted and controlled release of antimicrobial ions in the oral microbiome (5).

Furthermore, ion-embedded zeolite may serve as a potential antimicrobial agent towards pathogenic oral microorganisms. When ions released from zeolite encounter specific oral microbes, it may hinder their development by causing the inactivation of key enzymes, interruption of RNA replication, and blockage of microbial respiration (5). Therefore, incorporation of cations into zeolite may potentially decrease oral bacterial growth when added to dental materials.

When zeolite is incorporated into dental materials for antimicrobial effect, it is also important to consider the effect on the mechanical properties of the material. Common activities such as mastication and speech exert forces on teeth and materials incorporated into dentition. Thus, it is critical to the efficacy of dental operations if the materials used can withstand these forces without compromising their strength. Properties imperative to the success of long-term dental operations include flexural strength, bond strength to tooth structure, compressive strength, setting time, and surface microhardness (6). If zeolite can be incorporated into dental materials without hindering their mechanical properties, there can be a potential reduction in oral infections while reducing failures of dental restorations.

In this systematic review, the antimicrobial and mechanical properties of zeolite in different branches of dentistry such as endodontics, prosthetics, implantology, and restorative dentistry are analyzed. Specifically, the available literature was reviewed to determine if adding silver (or zinc) zeolite to dental materials would increase the antimicrobial effectiveness without inhibiting the strength and hardness of materials. The aim of this systematic study was to review both in vitro and in vivo studies that evaluated the antimicrobial effects and mechanical properties of zeolite as a material in dentistry.

\section{Material and Methods}

\section{Literature search strategy}

An exhaustive search of PubMed, Ovid Medline, Scopus, Embase, and the Dentistry \& Oral Sciences Source was conducted between June 1, 2020 and August 17, 2020. All published studies within the databases were screened for eligibility. There were no limitations set on the year or language of the publication. A controlled vocabulary was used (MeSH terms in Pubmed, Subject Headings in Ovid Medline, Emtree terms in Embase) across all databases as well as a search for free terms in the titles and abstracts. The grey literature search was conducted through ProQuest Dissertations \& Theses Global and Trip Database. The searches through the electronic databases were separately completed by two authors (J.H. and S.L.). The following search terms were used: MeSH terms: "zeolites", "biomedical and dental materials", tkiva od ostalih metalnih iona poput bakra i žive $(3,4)$. Kad kationi postanu dostupni u okolnom oralnom okružju, zeolit mijenja te katione za ugrađene ione srebra. To se, pak, dogada samo uz prisutnost vlage i sve dok koncentracija srebra ne dostigne lokalnu vrijednost ravnoteže. Zato AgZ može osigurati ciljano i kontrolirano oslobađanje antimikrobnih iona u oralnom mikrobiomu (5).

Nadalje, zeolit $s$ ugrađenim ionima može poslužiti kao antimikrobno sredstvo za patogene oralne mikroorganizme. Kada ioni oslobođeni iz zeolita naiđu na određene mikroorganizme iz oralnoga mikrobima, mogu otežati njihov razvoj i prouzročiti inaktivaciju ključnih enzima, prekid replikacije RNK i blokadu mikrobnoga disanja (5). Zato ugradnja kationa u zeolit može smanjiti rast oralnih bakterija ako se dodaju u dentalne materijale.

Kada se zeolit dodaje u dentalne materijale radi antimikrobnog učinka, također je važno uzeti u obzir učinak na mehanička svojstva materijala. Uobičajene aktivnosti, poput žvakanja i govora, čine silu na zube i dentalne materijale. Zato je presudno da upotrijebljeni materijali mogu podnijeti tu silu bez ugrožavanja integriteta. Svojstva nužna za dugoročni uspjeh nadomjestaka uključuju savojnu čvrstoću, veznu čvrstoću sa zubnom strukturom, tlačnu čvrstoću, vrijeme stvrdnjavanja i mikrotvrdoću površine (6). Ako se zeolit može ugraditi u dentalne materijale, a da se pritom ne poremete njihova mehanička svojstva, mogu se potencijalno smanjiti oralne infekcije, uz istodobno smanjenje oštećenja na zubnim nadomjestcima.

$\mathrm{U}$ ovom sistematiziranom preglednom radu analiziraju se antimikrobna i mehanička svojstva zeolita u različitim granama stomatologije, poput endodontskih zahvata, protetike, implantologije i restaurativne stomatologije. Točnije, pregledana je objavljena literatura kako bi se utvrdilo hoće li dodavanje zeolita sa srebrom (ili cinkom) dentalnim materijalima povećati antimikrobnu učinkovitost bez inhibiranja čvrstoće i tvrdoće materijala. Cilj ovog istraživanja bio je pregledati istraživanja in vitro i in vivo u kojima su autori procjenjivali antimikrobne učinke i mehanička svojstva zeolita kao materijala u stomatologiji.

\section{Materijali i metode}

\section{Strategije pretraživanja literature}

Ovaj sustavni pregled proveden je u skladu sa smjernicama PRISMA-e (Preferred Reporting Items for Systematic Reviews and Meta-Analyses - Preferirane stavke izvještavanja za sustavne pregledne radove i metaanalize), tablica 1 .

Obavljena je iscrpna pretraga baza Pubmed, Ovid Medline, Scopus, Embase te Dentistry i Oral Sciences Source između 1. lipnja i 17. kolovoza 2020. Sva objavljena istraživanja u bazama podataka provjerena su kako bi se utvrdilo ispunjavaju li uvjete za uključivanje. Nisu postavljena ograničenja za godinu ili jezik izdanja. U svim bazama podataka korišten je kontrolirani rječnik (MeSH u Pubmedu, Subject Headings u Ovid Medlineu, Emtree terms u Embaseu) te slobodni pojmovi u naslovima i sažetcima. Pretraživanje sive literature provedeno je u bazi ProQuest Dissertations i Theses 
"dental cavity lining", "resin cements", "dental cements", "dental restoration, permanent", "dental restoration, temporary", "composite resins", "ceramics", "dental porcelain", "dental veneers", "dentures", "acrylic resin"; Subject Headings: "dental cements", "dental cavity lining", "resin cements", "dental restoration, permanent"; "composite resin", "ceramics", "dental porcelain", "dental veneers", "dentures", "acrylic resin"; Emtree Terms: "dental materials", "resin cement", "dental restoration", "dentures", "dental porcelain", "dental veneers", "composite resin", "dental prosthesis and implant", "biomedical and dental materials." Free Terms: zeolite, clinoptilolite, dental materials, dental cements, dental restoration, dental base material, dental liners, dental ceramics, dental porcelain, dental veneers, dentures, dental acrylic resin.

\section{Eligibility Criteria}

Studies that pertained to the usage of zeolite in dental materials such as composite resin, bonding agents, cements, restorative root material, cavity base material, prosthesis, implants, and endodontics were included in this systematic review. In addition, only full texts were selected for inclusion. Zeolite used in oral rinses or oral medicaments was excluded as well as those studies pertaining to tissue conditioners. Literature reviews and abstracts were excluded to meet the fulltext-only eligibility criteria.

\section{Screening and Selection}

The studies that were collected were screened independently by two researchers (J.H. and S.L.) for titles and abstracts that met the identified inclusion criteria. Differences in opinions were discussed between the two researchers until a consensus was reached. Following the discussion, the two reviewers separately screened the selected full texts for eligibility. Disagreements were discussed until a consensus was reached. Due to the COVID-19 pandemic, the numbers of active libraries were smaller than normal. Therefore, with all resources exhausted, the full texts of 3 chosen articles were still unable to be procured and included in the analysis portion of the systematic review. At last, the references of the selected articles were reviewed, and eligibility was determined based on the inclusion criteria. Disagreements were resolved between the two reviewers and discussions with a mentor (F.O.).

\section{Data Extraction}

Prior to data extraction, a protocol was agreed upon by two of the authors (J.H. and S.L.). Data were then extracted from the selected full text articles and organized on an excel sheet. The two authors extracted the data including authors, publication year, type of study, antimicrobial/mechanical properties, sample size, materials used, results, microbes tested, and risk of bias, Table 1, Table 2.

\section{Assessment of Risk of Bias of Reviewed Papers}

For in vitro studies and randomized control trials, the risk of bias assessment was considered based on a previous study
Global and Trip Database. Pretrage elektroničkih baza podataka odvojeno su provela dva autora (J. H. i S. L.). Korišteni su sljedeći pojmovi za pretraživanje: $\mathrm{MeSH}$ pojmovi: zeolit, biomedicinski i dentalni materijali, kavitetne podloge, smolasti cementi, zubni cementi, zubna restauracija - trajna, zubna restauracija - privremena, kompozitne smole, keramika, dentalna keramika, zubne ljuske, proteze, akrilatna smola; Subject Headingd: zubni cementi, kavitetne podloge, smolasti cementi, zubna restauracija - trajna; kompozitna smola, keramika, dentalna keramika, zubne ljuske, proteze, akrilatna smola; Emtree terms: dentalni materijali, smolasti cement, zubna restauracija, proteze, dentalna keramika, zubne ljuske, kompozitna smola, zubna proteza $i$ implantat, biomedicinski i dentalni materijali. Slobodni pojmovi: zeolit, klinoptilolit, dentalni materijali, dentalni cementi, restauracija zuba, materijal za podloge, kavitetne podloge, dentalna keramika, zubne ljuske, proteze, akrilatna smola, tablica 2.

\section{Kriteriji prihvatljivosti}

Istraživanja koja su se odnosila na upotrebu zeolita u dentalnim materijalima kao što su kompozitne smole, adhezivi, cementi, korijenski materijali, kavitetne podloge, materijali za protetiku, implantologiju i endodoncija uključena su u ovaj sistematizirani pregled. Odabrani su samo cjeloviti tekstovi. Izuzeti su zeoliti koji se upotrebljavaju u oralnim otopinama za ispiranje ili za oralne lijekove te oni koji se primjenjuju u regeneraciji tkiva. Recenzije literature i sažetci su izuzeti.

\section{Pregled i odabir}

Dva istraživača (J. H. i S. L.) neovisno su pregledala prikupljena istraživanja prema naslovima i sažetcima koji su zadovoljili utvrđene kriterije za uključivanje. U slučaju neslaganja razgovarali su o razlikama u mišljenju dok nisu postigli konsenzus. Nakon završene rasprave dva recenzenta odvojeno su pregledala odabrane cjelovite tekstove kako bi ustanovili ispunjavaju li uvjete. $\mathrm{O}$ nesuglasicama su raspravljali dok nije postignut konsenzus. Zbog pandemije virusa COVID-19 broj knjižnica koje rade bio je manji od uobičajenoga. Stoga, nakon što su svi resursi iscrpljeni, cjeloviti tekstovi triju odabranih radova nisu bili dostupni te se nisu mogli uključiti u dio o analizi ovoga sustavnoga preglednog rada. $\mathrm{Na}$ kraju je pregledana literatura odabranih radova i utvrđena je prihvatljivost na temelju kriterija za uključivanje. Riješene su nesuglasice između dvaju recenzenata i obavljen je razgovor $s$ mentorom (F. O.)

\section{Vađenje podataka}

Prije vađenja podataka, dva autora (J. H. i S. L.) dogovorila su protokol. Podatci su zatim izvučeni iz odabranih radova s cjelovitim tekstom i organizirani na Excel tablici. Zatim su izdvojeni podatci, uključujući autore, godinu izdanja, vrstu istraživanja, antimikrobna/mehanička svojstva, veličinu uzorka, upotrijebljene materijale, rezultate, testirane mikrobe i rizik od pristranosti, tablica 1, tablica 2 .

\section{Procjena rizika od pristranosti pregledanih radova}

Za randomizirana kontrolirana istraživanja in vitro provedena je procjena rizika od pristranosti na temelju prethodnog 
(7), and each study was assessed on the basis of the following five parameters: I) sample size, II) presence of control, III) blinding of the operator, IV) standardized sample preparation, and $\mathrm{V}$ ) single operator.

For each parameter I-IV, a score of 0 was given to an article if the criteria were reported clearly, a score of 1 was given to an article if the criteria were vague or insufficiently reported, and a score of 2 was given to an article if the information was not present. For parameter $\mathrm{V}$, a score of 0 was given to an article if there was one operator, a score of 1 was given to an article if there were more operators, and a score of 2 was given to an article if the information was not present.

The five parameter scores for each article were then added for a cumulative score. Articles that were at low risk of bias scored between $0-3$, moderate risk of bias scored between 4-7, and high risk of bias scored between 8-10. Two authors (J.H. and S.L.) independently assessed the risk of bias criteria for each article in duplicate, and any disagreements during the evaluation were later discussed and a consensus was reached.

\section{Inter-Rater Reliability (IRR)}

An Inter-Rater Reliability (IRR) test within the risk of bias test was conducted using a kappa calculator. Percent user agreement was calculated by taking the number of studies given the same risk of bias scores by both authors and dividing it by the total number of studies. The same risks of bias scores were considered in order to use the Cohen's Kappa test (8), and the resulting kappa values are reported, Table 2. To obtain the percent data that are reliable, the kappa values were squared. From these percentages, a level of agreement was described for each parameter (8).

\section{Results}

\section{Search and Selection}

The selection process is summarized in the Prisma Flow Chart shown in Figure 1 following Moher et al. (9). A database, grey literature, and reference search yielded 1534 studies, of which 687 duplicate records were excluded. The remaining 847 records were screened for title and abstract, and 801 were removed since they did not meet the eligibility criteria. 46 remaining articles were assessed for eligibility by examining the full-texts, and 11 articles did not meet the eligibility criteria and were therefore excluded. Of the remaining 35 articles included in the qualitative synthesis, 17 studied antimicrobial effects, 12 studied mechanical properties, and 6 studied both properties, Table 1 .

\section{Risk of Bias Test of the Studies in the Systematic Review}

Supplementary [S3 Table] shows the risk of bias data of the 35 articles analyzed following the methods outlined by Astudillo-Rubio et al. (7). As shown in the table, the majority of papers were given a score of 2 by both authors in the "blinding operator" and "single operator" parameters for failing to provide any pertinent information. All studies had a moderate risk of bias except three studies with low, and one study with high risk of bias (9-15). The study with a high risk of bias score failed to use a control and did not reveal any istraživanja (7), a svaki rad procijenjen je na temelju sljedećih pet parametara: 1) veličine uzorka, 2) prisutnosti kontrole, 3) zasljepljivanja istraživača, 4) standardizirane pripreme uzoraka i 5) broja ocjenjivača.

Za svaki parametar od 1 do 4 istraživanje je dobilo ocjenu 0 ako su kriteriji jasno navedeni, 1 ako je kriterij bio nejasan ili nedovoljno objašnjen, a ocjenu 2 ako informacija nije bilo. Za parametar 5 rad je dobio ocjenu 0 ako postoji jedan procjenitelj, ocjenu 1 ako je u radu bilo više od jednog procjenitelja, a ocjenu 2 ako podatci o broju procjenitelja nisu navedeni.

Tada su za svaki rad zbrojene ocjene za svaki parametar da bi se dobio kumulativni rezultat. Radovi s malim rizikom od pristranosti postigli su ocjenu od 0 do 3 , umjereni rizik od pristranosti ocjenu od 4 do 7 i visoki rizik od pristranosti ocjenu od 8 do 10. Dva su autora (J. H. i S. L.) neovisno procjenjivala rizik kriterija pristranosti za svaki rad, a poslije su tijekom procjene raspravljali o svim neslaganjima dok nisu postigli konsenzus.

\section{Pouzdanost među ocjenjivačima (IRR)}

Test pouzdanosti među ocjenjivačima (IRR), u sklopu procjene rizika od pristranosti, proveden je Kappa testom. Postotak podudaranja izračunat je uzimajući broj istraživanja s jednakim rizikom od pristranosti obaju autora i dijeleći ga s ukupnim brojem istraživanja. Jednaki rizik od pristranosti korišten je za provođenje Cohenova Kappa testa (8), a dobiveni rezultati prikazani su u tablici 2. Da bi se dobili pouzdani podatci o postotku, Kappa vrijednosti su pomnožene na kvadrat. Iz tih postotaka opisana je razina podudaranja za svaki parametar (8).

\section{Rezultati}

\section{Pretraživanje i odabir}

Proces odabira sažet je u dijagramu PRISMA prikazanom na slici 1., prema Moheru i suradnicima (9). U bazama podataka, sivoj literaturi i pretraživanjem referencija pronađena su 1534 istraživanja od kojih je 687 dvostrukih zapisa isključeno. Preostalih 847 pregledano je prema naslovu i sažetku, a 801 je izbačen jer nisu zadovoljavali kriterije. Preostalih 46 radova ocijenjeno je nakon što su pregledani cjeloviti tekstovi kako bi se ustanovilo ispunjavaju li uvjete, a 11 radova nije zadovoljavalo kriterije prihvatljivosti te su isključeni. Od preostalih 35 radova uključenih u kvalitativnu sintezu, autori 17 njih proučavali su antimikrobne učinke, 12 mehanička svojstva, a 6 oba svojstva, tablica 1 .

\section{Testiranje rizika od pristranosti istraživanja iz sistematiziranog pregleda}

Sva istraživanja imala su umjereni rizik od pristranosti, osim triju s niskim i jednim istraživanjem $s$ visokim rizikom od pristranosti (9-15). U istraživanju s visokim rizikom od pristranosti nije bilo kontrole i nisu otkriveni nikakvi podatci o ocjenitelju. Nadalje, oba su autora podatke o veličini uzorka i standardiziranoj pripremi uzorka smatrali nejasnima. No rad se uklapao u kriterije za uključivanje koje su odredili autori pa je uključen kako se ne bi uskratile nikakve relevantne informacije. 
PRISMA 2009 Flow Diagram

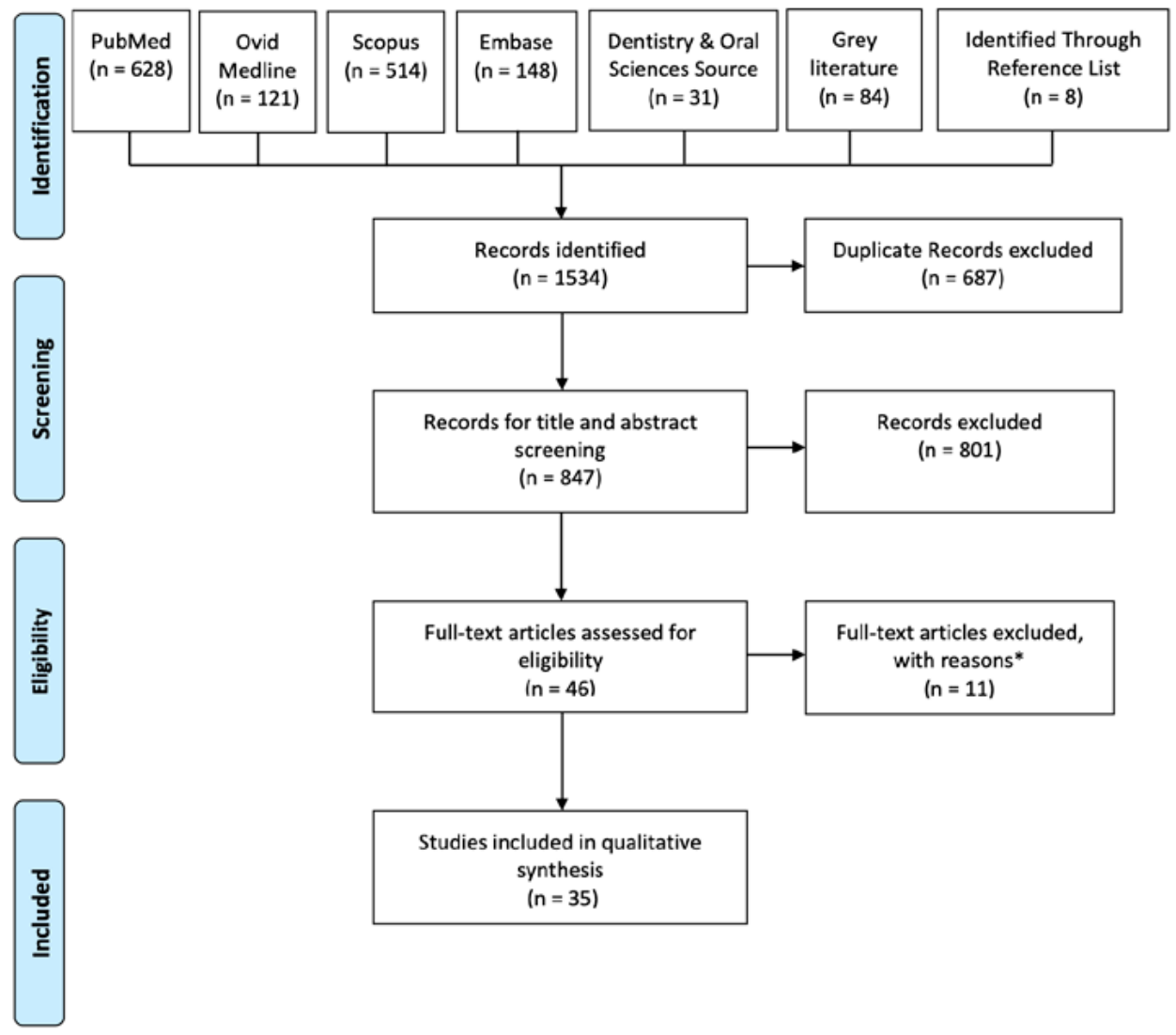

Figure 1 The Prisma Flow Diagram

*: 2 studied remineralizing potential, 1 studied biocompatibility, 2 studied color stability, 1 studied porosity, 1 studied surface roughness, 3 were unable to be accessed due to COVID-19 library closures, 1 unable to be accessed in English.

For more information on the PRISMA Flow Chart, visit www.prisma-statement.org.

Slika 1. Prisma dijagram

*: dva su proučavala remineralizacijski potencijal, jedan biokompatibilnost, dva stabilnost boje, jedan poroznost, jedan hrapavost površine, trima nije bilo moguće pristupiti zbog zatvaranja knjižnice zbog virusa COVID-19, jednomu nije bilo moguće pristupiti na engleskom jeziku.

Za više informacija o PRISMA dijagramu posjetite www.prisma-statement.org.

information about the operator. Furthermore, information about sample size and standardized sample preparation were considered vague by both authors. However, the paper met the inclusion criteria considered by the authors; hence it was included in order not to withhold any relevant information.

\section{Inter-rater Reliability Results}

The results of IRR tests for each risk of bias parameter are shown in Table 2. All parameters showed at least $74 \%$ or higher in percent user agreement and the average percent user agreement across all five parameters was $89.06 \%$. The average percent of data that are reliable, as determined by Cohen's Kappa Test, is $46.6 \%$, indicating an overall moderate level of reliability. Because the risk of bias test included 3 different possible scores, the discrepancies between authors were due to whether the parameters in question were clearly specified in the studies. Therefore, most of the score differences were due to one author judging an article as clearly reporting the parameter, while the other author judged the article

\section{Rezultati pouzdanosti između ocjenjivača}

Rezultati IRR testova za svaki parametar rizika od pristranosti prikazani su u tablici 2. U svim je parametrima postignut postotak od najmanje $74 \%$ ili podudarnost među ocjenjivačima, a prosječni postotak podudarnosti u svih pet parametara bio je $89,06 \%$. Prosječni postotak pouzdanih podataka, kako je utvrđeno Cohenovim Kappa testom, iznosio je 46,6 \%, što upućuje na ukupno umjerenu razinu pouzdanosti. Budući da je test pristranosti obuhvaćao tri različita moguća rezultata, neslaganja između ocjenjivača nastala su ovisno o tomu jesu li parametri jasno navedeni u istraživanjima. Zato je većina razlika nastala zato što je jedan autor ocijenio da se u radu jasno navodi traženi parametar, a drugi je 
Table 1 Summary of the studies included in the systematic review

Tablica 1. Sažetak istraživanja uključenih u sistematizirani pregledni rad

\begin{tabular}{|c|c|c|c|c|c|c|}
\hline $\begin{array}{l}\text { Author, Year • } \\
\text { Autor, godina }\end{array}$ & 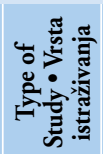 & $\begin{array}{c}\text { Property } \\
\text { Svojstvo }\end{array}$ & $\mathbf{n}$ & $\begin{array}{l}\text { Materials Used • } \\
\text { Korišteni materijali }\end{array}$ & Results $\bullet$ Rezultati & $\begin{array}{l}\text { Microbes Tested } \\
\text { Testirani mikrobi }\end{array}$ \\
\hline $\begin{array}{c}\text { Saengmee-Anupharb } \\
\text { et al [10] } \\
(2013)\end{array}$ & In vitro & A & 3 per group & AgZ, AgZrPSi, AgZrP & $\begin{array}{l}\text { All inorganic materials with } \\
\text { silver had antimicrobial effects. }\end{array}$ & $\begin{array}{l}\text { S. mutans, } \text { L. casei, } \\
\text { C. albicans, S. aureus }\end{array}$ \\
\hline $\begin{array}{l}\text { Cinar et al [14] } \\
\text { (2008) }\end{array}$ & In vitro & A & 5 per material & GIC (Endion), AgZ & $\begin{array}{l}\mathrm{AgZ} \text { increased the } \\
\text { antimicrobial effects }\end{array}$ & $\begin{array}{l}\text { S. milleri, S. aureus, } E \text {. } \\
\text { faecalis }\end{array}$ \\
\hline $\begin{array}{c}\text { Can-Karabulut et } \\
\text { al [21] } \\
(2010)\end{array}$ & In vitro & M & 10 per material & $\begin{array}{c}\text { GIC, zeolite, bone } \\
\text { hydroxyapatite, provisional } \\
\text { cement }\end{array}$ & $\begin{array}{l}\text { Bond strength decreased with } \\
\text { zeolite in cement. }\end{array}$ & N/A \\
\hline $\begin{array}{l}\text { Chung et al [20] } \\
\text { (2001) }\end{array}$ & RCT & M & $\begin{array}{l}10 \text { per } \\
\text { subgroup }\end{array}$ & Ketac-Endo, KT-308, ZUT & $\begin{array}{l}\text { ZUT and KT-308 showed } \\
\text { highest bond strength. }\end{array}$ & N/A \\
\hline $\begin{array}{l}\text { Ghatole et al [28] } \\
\qquad(2016)\end{array}$ & In vitro & A & 3 per group & MTA, AgZ, CHX & $\begin{array}{l}\text { MTA with } \mathrm{AgZ} \text { showed the } \\
\text { greatest efficacy against } E \text {. } \\
\text { faecalis. }\end{array}$ & E. faecalis \\
\hline $\begin{array}{l}\text { Ghivari et al [25] } \\
\text { (2017) }\end{array}$ & In vitro & A & 5 per material & $\begin{array}{l}\text { Na Hypochlorite, } \\
\text { Octenidine, AgZ }\end{array}$ & $\begin{array}{c}\mathrm{AgZ} \text { showed the least } \\
\text { antimicrobial effectiveness. }\end{array}$ & $\begin{array}{l}\text { E. faecalis, } S \text {. aureus, } C \text {. } \\
\text { albicans }\end{array}$ \\
\hline $\begin{array}{l}\text { Hotta et al [3] } \\
\quad(1998)\end{array}$ & In vitro & B & 6 per group & $\begin{array}{c}\mathrm{Ag}-\mathrm{Zn}-\mathrm{Zeolite} \\
\mathrm{SiO} 2 \text { filler and urethane } \\
\text { acrylate paste }\end{array}$ & $\begin{array}{l}\mathrm{Ag}-\mathrm{Zn}-\mathrm{Ze} \text { inhibited } S \text {. } \\
\text { mutans and } S \text {. mitis but not } S \text {. } \\
\text { salivarius or } S . \text { sanguis. }\end{array}$ & $\begin{array}{l}\text { S. mutans, } \text { S. mitis, } \\
\text { S. salivarius, S. sanguis }\end{array}$ \\
\hline $\begin{array}{c}\text { Kawahara et al [4] } \\
\text { (2000) }\end{array}$ & In vitro & A & 6 per group & Zeomic, AgZ & $\begin{array}{l}\text { AgZ inhibited microbial } \\
\text { growth under anaerobic } \\
\text { conditions. }\end{array}$ & $\begin{array}{c}\text { P. gingivalis } \\
\text { actinomycetemcomitans, } \\
\text { S. mutans, A. viscosus, } S . \\
\text { aureus }\end{array}$ \\
\hline $\begin{array}{l}\text { Kim et al [16] } \\
\quad(2016)\end{array}$ & In vitro & B & $\mathrm{N} / \mathrm{S}$ & $\begin{array}{l}\text { CHX-loaded zeolite } \\
\text { nanoparticles, GIC }\end{array}$ & $\begin{array}{l}\text { GIC + CHX/Zeolite inhibited } \\
\text { S. mutans. No decrease in } \\
\text { compressive or bond strength }\end{array}$ & S. mutans \\
\hline $\begin{array}{l}\text { Kuroki et al [37] } \\
\quad(2010)\end{array}$ & In vitro & A & 6 per material & $\begin{array}{c}\text { self-cured acrylic resin } \\
\text { (UNIFAST III), } \\
\text { zeomic, bactekiller, novaron }\end{array}$ & $\begin{array}{l}\text { Adding zeomic decreased } S \text {. } \\
\text { mutans }\end{array}$ & S. mutans \\
\hline $\begin{array}{l}\text { Lee et al [13] } \\
\quad(2007)\end{array}$ & In vitro & B & $\mathrm{N} / \mathrm{S}$ & Zeomic, GIC & $\begin{array}{c}\text { Zeomic improved } \\
\text { antimicrobial properties. Below } \\
3 \% \text { wt retained compressive } \\
\text { strength. }\end{array}$ & S. mutans \\
\hline $\begin{array}{l}\text { Li et al [23] } \\
\quad(2020)\end{array}$ & RCT & A & $\mathrm{N} / \mathrm{S}$ & $\begin{array}{l}\text { EMT nano-zeolites, silver } \\
\text { ions, } \\
\text { dental adhesive (ASB2) }\end{array}$ & $\begin{array}{l}\text { Inhibited biofilm growth/ } \\
\text { attachment. }\end{array}$ & $\begin{array}{l}\text { S. mutans, } \\
\text { S. gordonii, } \\
\text { S. sanguinis }\end{array}$ \\
\hline $\begin{array}{l}\text { Mabrouk et al [15] } \\
\text { (2013) }\end{array}$ & In vitro & A & $\mathrm{N} / \mathrm{S}$ & ZnZ, AgZ, GIC & $\begin{array}{l}\text { Adding } \mathrm{ZnZ} \text { or } \mathrm{AgZ} \text { to GIC } \\
\text { inhibited bacteria. }\end{array}$ & $\begin{array}{l}\text { B. subtilis, C. albicans, } \\
\text { E. coli, S. aureus }\end{array}$ \\
\hline $\begin{array}{c}\text { Padachey et al [18] } \\
\text { (2000) }\end{array}$ & In vitro & A & 10 per group & GIC, gutta percha, ZUT & $\begin{array}{l}\text { ZUT was not more effective } \\
\text { than GIC. But gutta percha } \\
\text { improved the resistance to } \\
\text { bacterial ingress. }\end{array}$ & E. faecalis \\
\hline $\begin{array}{c}\text { Partoazar et al [11] } \\
(2019)\end{array}$ & In vitro & A & $\mathrm{N} / \mathrm{S}$ & $\begin{array}{l}\text { nano- } \mathrm{ZnO} \text { zeolite, } \mathrm{ZnO} \\
\text { zeolite }\end{array}$ & $\begin{array}{l}\text { NanoZnO/zeolite was effective } \\
\text { in inhibiting E. faecalis biofilm }\end{array}$ & E. faecalis \\
\hline $\begin{array}{l}\text { Cinar et al [29] } \\
\quad(2013)\end{array}$ & In vitro & M & 3 per material & MTA powder, AgZ & $\begin{array}{l}\text { Adding AgZ to MTA didn't } \\
\text { decrease physio-chemical } \\
\text { properties. }\end{array}$ & N/A \\
\hline $\begin{array}{l}\text { El-Guindy et al [24] } \\
\qquad(2010)\end{array}$ & In vitro & M & $\begin{array}{l}30 \text { per group, } \\
10 \text { per } \\
\text { subgroup }\end{array}$ & $\begin{array}{l}\text { Rely X Unicem, G bond, } \\
\text { ZnZ }\end{array}$ & $\begin{array}{l}\text { Pretreatment of dentin with } \mathrm{G} \\
\text { bond and } \mathrm{ZnZ} \text { increased bond } \\
\text { strength between dentin/alloy. }\end{array}$ & N/A \\
\hline $\begin{array}{l}\text { Ghasemi et al [30] } \\
\text { (2019) }\end{array}$ & In vitro & M & 20 per group & $\begin{array}{c}\text { MTA powder, } 2 \% \mathrm{Ag}-\mathrm{Zn}-\mathrm{Ze} \\
\text { composite }\end{array}$ & $\begin{array}{l}\text { MTA with } 2 \% \text { Ag-Zn-Ze } \\
\text { decreased push-out bond } \\
\text { strength. }\end{array}$ & N/A \\
\hline $\begin{array}{l}\text { Ghatole et al [26] } \\
\text { (2016) }\end{array}$ & In vitro & A & 4 per group & $\begin{array}{c}\text { Calcium hydroxide, } \mathrm{AgZ}, \\
2 \% \mathrm{CHX}\end{array}$ & $\begin{array}{c}\mathrm{AgZ} \text { in calcium hydroxide } \\
\text { increased antimicrobial activity }\end{array}$ & E. faecalis \\
\hline $\begin{array}{l}\text { Casemiro et al [40] } \\
\text { (2008) }\end{array}$ & In vitro & B & 10 per group & $\begin{array}{l}\text { Microwave-polymerized } \\
\text { acrylic resin, Heat- } \\
\text { polymerized resins, } \mathrm{AgZ}\end{array}$ & $\begin{array}{c}\text { Acrylic resin with } \mathrm{Ag}-\mathrm{Zn}-\mathrm{Ze} \\
\text { increased antimicrobial effects. }\end{array}$ & C. albicans and S. mutans \\
\hline $\begin{array}{l}\text { Malic et al [38] } \\
\quad(2019)\end{array}$ & In vitro & A & 6 per group & $\begin{array}{l}\text { Dental acrylics, AgZ, Na- } \\
\text { zeolite }\end{array}$ & $\begin{array}{c}\text { Adding zeolite to dental } \\
\text { acrylics increased antimicrobial } \\
\text { effect. }\end{array}$ & $\begin{array}{l}\text { S. mutans, F. nucleatum, } \\
\text { C. albicans }\end{array}$ \\
\hline
\end{tabular}




\begin{tabular}{|c|c|c|c|c|c|c|}
\hline $\begin{array}{l}\text { Odabas et al [27] } \\
\quad(2011)\end{array}$ & In vitro & A & 5 per group & AgZ, MTA & $\begin{array}{l}\text { MTA with zeolite increased } \\
\text { antimicrobial effects except } \\
\text { against } P \text {. intermedia and } A . \\
\text { israelii. }\end{array}$ & $\begin{array}{c}\text { S. aureus, E. faecalis, } E \text {. } \\
\text { coli, } \\
\text {, C. albicans, P. gingivalis, } \\
\text { C. A. israelii, P. } \\
\text { intermedia }\end{array}$ \\
\hline $\begin{array}{l}\text { Patel et al [17] } \\
\quad(2000)\end{array}$ & In vitro & A & 108 per group & KT-308, Zeomic & $\begin{array}{c}\text { Regardless of concentration, } \\
\text { all ZUT inhibited } E \text {. faecalis at } \\
15 \text { hours. }\end{array}$ & E. Faecalis \\
\hline $\begin{array}{c}\text { Sandomierski et al } \\
{[22]} \\
(2019)\end{array}$ & In vitro & M & 10 per material & $\begin{array}{l}\text { Zeolite filler, diazonium } \\
\text { cation } \\
\text { methacrylic resin-based } \\
\text { composite }\end{array}$ & $\begin{array}{l}\text { Diazonium-modified zeolite } \\
\text { fillers improved compressive } \\
\text { and flexural strength. }\end{array}$ & N/A \\
\hline $\begin{array}{c}\text { Saravanan et al [32] } \\
(2015)\end{array}$ & In vitro & A & 30 patients & $\mathrm{AgZ}$, soft liners & $\begin{array}{l}\text { Soft liner with } \mathrm{AgZ} \text { inhibited } \\
\text { bacterial growth }\end{array}$ & $\begin{array}{l}\text { c. albicans, gram negative } \\
\text { bacteria }\end{array}$ \\
\hline $\begin{array}{c}\text { Tamanai-Shacoor et } \\
\text { al [12] } \\
(2014) \\
\end{array}$ & In vitro & B & 3 per group & AgZ, ASCOP & $\begin{array}{l}\text { AgZ with ASCOP inhibited } P \text {. } \\
\text { gingivalis but not } S \text {. gordonii } \\
\text { growth. }\end{array}$ & P. gingivalis, S. gordonii \\
\hline $\begin{array}{l}\text { Naji et al [34] } \\
\quad(2017)\end{array}$ & In vitro & M & 10 per group & $\begin{array}{l}\text { Sodalite, alumina, ZTA, } \\
\text { glass }\end{array}$ & $\begin{array}{c}\text { Sodalite-infiltrated ceramics } \\
\text { had higher shear bond strength } \\
\text { than glass-infiltrated. }\end{array}$ & N/A \\
\hline $\begin{array}{l}\text { Naji et al [35] } \\
\quad(2018)\end{array}$ & In vitro & M & 20 per group & $\begin{array}{l}\text { KBr-Sodalite, porous } \\
\text { alumina, ZTA }\end{array}$ & $\begin{array}{l}\text { Increasing sintering temp } \\
\text { of SOD-ZTA/A increased } \\
\text { hardness and bond strength. }\end{array}$ & N/A \\
\hline $\begin{array}{l}\text { Naji et al [33] } \\
\quad(2016)\end{array}$ & In vitro & M & 10 per group & $\begin{array}{c}\text { sodalite, zeolite-infiltrated } \\
\text { alumina (IA-SOD), ZTA, } \\
\text { glass } \\
\end{array}$ & $\begin{array}{l}\text { Sodalite-infiltrated ZTA had } \\
\text { increased fracture toughness. }\end{array}$ & N/A \\
\hline $\begin{array}{l}\text { Naji et al [36] } \\
\quad(2016)\end{array}$ & In vitro & M & 10 per group & $\begin{array}{l}\text { Sodalite, alumina, ZTA, } \\
\text { glass }\end{array}$ & $\begin{array}{c}\text { Sodalite infiltrated alumina and } \\
\text { ZTA were in the acceptable } \\
\text { range of hardness and flexural } \\
\text { strength. }\end{array}$ & N/A \\
\hline $\begin{array}{l}\text { Yadav et al [41] } \\
\qquad(2015)\end{array}$ & In vitro & M & 10 per group & $\begin{array}{l}\text { Fluconazole, CHX } \\
\text { Gluconate, } \\
\text { Ag-Zn-Ze, PMMA }\end{array}$ & $\begin{array}{c}\text { Flexural strength decreased } \\
\text { significantly }\end{array}$ & N/A \\
\hline $\begin{array}{c}\text { Nakanoda et al [39] } \\
\text { (1995) }\end{array}$ & In vitro & B & 4 per group & Zeomic, acrylic resin & $\begin{array}{c}\text { Tensile and bending strength } \\
\text { decreased in zeolite containing } \\
\text { resin, }\end{array}$ & C. albicans \\
\hline $\begin{array}{l}\text { Samiei et al [31] } \\
\quad(2017)\end{array}$ & In vitro & M & 15 per group & MTA, $2 \%$ Ag-Zn-Ze & $\begin{array}{l}\text { Mixing MTA with 2\% Ze- } \\
\text { Ag-Zn decreased compressive } \\
\text { strength. }\end{array}$ & N/A \\
\hline $\begin{array}{l}\text { Wang et al [42] } \\
\text { (2011) }\end{array}$ & In vitro & A & 3 per material & $\begin{array}{c}\text { Titanium alloy, AgZ, ZTA, } \\
\text { AgZ titanium alloy }\end{array}$ & $\begin{array}{l}\text { Zeolite coating on implant } \\
\text { reduced bacterial growth }\end{array}$ & S. aureus \\
\hline $\begin{array}{c}\text { McDougall et al } \\
{[19]} \\
(1999)\end{array}$ & In vitro & A & 10 per group & $\begin{array}{l}\text { ZUT, Kerr sealer, KT-308, } \\
\text { gutta percha }\end{array}$ & $\begin{array}{l}\text { E. faecalis penetration increased } \\
\text { in canals filled with ZUT }\end{array}$ & E. faecalis \\
\hline
\end{tabular}

Abbreviations: N/S: Not Stated; N/A: Not Applicable; A: Antimicrobial; M: Mechanical; B: Both Antimicrobial and Mechanical; PMMA: Polymethylmethacrylate; ZTA: Zirconium Toughened Alumina; AgZ: Silver-Incorporated Zeolite; ZnZ: Zinc-Incorporated Zeolite; Ag-Zn-Ze: SilverZinc-Incorporated Zeolite; MTA: Mineral Trioxide Aggregate; GIC: Glass Ionomer Cement;

CHX: chlorhexidine; ZUT: AgZ with KT-308 GIC; Zeomic: a synthetic AgZ; ASCOP: polyphenol-rich extract of A. nodosum

\begin{tabular}{|c|c|c|c|c|}
\hline & $\begin{array}{c}\% \text { User Agreement }{ }^{\bullet} \\
\% \text { podudarnosti ocjenjivača }\end{array}$ & Карра & $\begin{array}{c}\% \text { data that are reliable (through } \\
\text { Cohen's Kappa Test) } \\
\text { \% pouzdanih podataka } \\
\text { (Cohenov Kappa test) }\end{array}$ & $\begin{array}{l}\text { Level of Agreement } \\
\text { Stupanj podudarnosti }\end{array}$ \\
\hline Sample Size • Veličina uzorka & $80 \%$ & 0.304 & $9.24 \%$ & Minimal $\bullet$ Minimalan \\
\hline Control $\bullet$ Kontrola & $97 \%$ & 0.788 & $62.10 \%$ & Moderate $\bullet$ Umjeren \\
\hline $\begin{array}{l}\text { Blinding Operator • } \\
\text { Zaslijepljeni istraživač }\end{array}$ & $100.00 \%$ & 1 & $100 \%$ & Almost Perfect $\bullet$ Gotovo savršen \\
\hline Single Operator $\bullet$ Broj ocjenjivača & $94 \%$ & 0.693 & $40.80 \%$ & Moderate $\bullet$ Umjeren \\
\hline $\begin{array}{l}\text { Standardized Sample Prep } \bullet \\
\text { Priprema standardiziranog uzorka }\end{array}$ & $74.30 \%$ & 0.457 & $20.90 \%$ & Weak • Slab \\
\hline
\end{tabular}


as vaguely or insufficiently reporting the parameter. This was highlighted with the sample size parameter, in which the authors initially disagreed on whether the details surrounding the sample size were elaborated sufficiently. Another parameter with a low level of agreement was the standardized sample preparation. The disagreements among the authors regarding this parameter were explained by the variability in extent to which each article specifically stated that they conducted a standardized procedure. All disagreements were resolved after discussion among the authors.

\section{Discussion}

Thirty-five in vitro studies and randomized control trials were evaluated to assess the effects of zeolite on the antimicrobial and/or mechanical properties of dental materials. Generally, zeolite itself had little to no effect on antimicrobial properties unless there was an incorporation of ions such as silver or zinc. In addition, ion-incorporated zeolite exhibited prolonged ion release and can serve as a long-term antimicrobial material $(4,10-12)$. The present systematic review evaluates such properties by grouping the literature into four major categories based on the type of dental material tested: dental restorations, endodontics, prosthetics, and implants.

\section{Dental Restorations}

Regarding dental restorative materials, zeolite was generally combined with glass ionomer cements (GIC), resin cements, or bonding agents $(3,13-23)$.

\section{Glass lonomer Cement}

When an ion-incorporated zeolite was combined with GIC, the antimicrobial effects were usually measured by an in vitro ion release profile or an agar diffusion test. As the ratio of $\mathrm{AgZ}$ by weight was increased, the inhibitory effect towards oral bacteria such as $S$. mutans would also increase (13). Similarly, 2\% AgZ had the greatest antimicrobial properties against $S$. milleri, $S$. aureus, and $E$. faecalis compared to $0.2 \%$ and $0 \% \mathrm{AgZ}$ (14). It is important to note that while GIC alone can only provide a rapid release of fluoride for two days, AgZ GIC can provide sustained release of silver ions for long periods of time (13). Similar antimicrobial results to $\mathrm{AgZ}$ can also be found in zinc-incorporated zeolite (ZnZ) against $E$. coli, $S$. aureus, P. aureginosa, B. subtilis, and C. albicans (15). In addition, zeolite in GIC can also have effective antimicrobial properties against $S$. mutans when it is loaded with chlorhexidine (16). For GIC used as root canal sealers, the antimicrobial effectiveness against $E$. faecalis had mixed results $(17,18)$. ZUT, a combination of $0.2 \% \mathrm{AgZ}$ by weight (wt) and a GIC sealer, KT-308, inhibited E. faecalis growth significantly more than KT-308 alone, regardless of concentration and time (17). On the other hand, Padachey et al. and McDougall et al. both concluded that ZUT was not more effective than the other $\operatorname{GIC}(18,19)$. The present results show that depending on the concentration of zeolite incorporated, GIC can have enhanced and sustained antimicrobial properties. However, the results may be affected by the use and type of GIC, and this could be a topic of further research. smatrao da je parametar nejasno ili nedovoljno naveden. To je istaknuto kod parametra veličine uzorka u kojem se autori na početku nisu složili o tome jesu li detalji o veličini uzorka dovoljno razrađeni. Sljedeći parametar s niskom razinom slaganja bio je standardizirana priprema uzorka. Nesuglasice između autora u vezi $s$ tim parametrom objašnjavaju se varijabilnošću u mjeri u kojoj je u svakomu radu posebno istaknuto da se provodio standardizirani postupak. Autori su sve nesuglasice riješili raspravom.

\section{Rasprava}

Ocijenjeno je trideset i pet randomiziranih kontroliranih istraživanja in vitro da bi se procijenili učinci zeolita na antimikrobna i/ili mehanička svojstva dentalnih materijala. Općenito, sam zeolit nije nimalo utjecao na antimikrobna svojstva, osim kada je bilo ugrađenih iona poput srebra ili cinka. $\mathrm{Uz}$ to, zeolit $\mathrm{s}$ ugrađenim ionima produljeno je oslobađao ione pa može poslužiti kao dugotrajni antimikrobni materijal $(4,10-12)$. Ovaj sistematizirani pregled ocjenjuje takva svojstva grupiranjem literature u četiri glavne kategorije na temelju vrste testiranoga dentalnog materijala. To su restaurativni materijali, endodoncija, proteze i implantati.

\section{Restaurativni materijali}

Kad je riječ o dentalnim restaurativnim materijalima, zeolit se obično kombinirao sa staklenoionomernim cementima (SIC), kompozitnim cementima ili adhezivima $(3,13$ 23).

\section{Staklenoionomerni cement}

Kada se zeolit s ugrađenim ionima kombinira sa SICom, antimikrobni učinci obično se mjere s pomoću in vitro profila oslobađanja iona ili agar-difuznim testom. Kako se povećava maseni udio AgZ-a, povećava se i inhibitorni učinak na oralne bakterije kao što je $S$. mutans (13). Slično tomu, $2 \%$ AgZ-a imalo je najveća antimikrobna svojstva kad je riječ o $S$. milleri, $S$. aureus i $E$. faecalis u usporedbi s 0,2 \% i 0 \% AgZ-a (14). Važno je napomenuti da sam SIC samo dva dana može osigurati brzo oslobađanje fluora, a SIC s AgZ-om može osigurati kontinuirano oslobađanje iona srebra tijekom duljeg razdoblja (13). Sličan antimikrobni učinak kao AgZ ima i zeolit s ugrađenim cinkom (ZnZ) protiv E. coli, S. aureus, P. aureginosa, B. subtilis i C. albicans (15). Uz to, zeolit u SIC-u može učinkovito antimikrobno djelovati na $S$. mutans kada je napunjen klorheksidinom (16). Za SIC koji se upotrebljava kao sredstvo za brtvljenje korijenskih kanala rezultati antimikrobne učinkovitosti na $E$. faecalis bili su mješoviti $(17,18)$. ZUT, kombinacija 0,2 mas.\% AgZ-a i SIC-a KT-308 inhibirala je rast $E$. faecalis znatno više od samoga KT-308, bez obzira na koncentraciju i vrijeme (17). S druge strane, Padachey i suradnici te McDougall i suradnici zaključili su da ZUT nije učinkovitiji od drugih SIC-ova $(18,19)$. Rezultati ovoga rada pokazuju da, ovisno o koncentraciji ugrađenoga zeolita, SIC može imati pojačana i dugotrajna antimikrobna svojstva. No uporaba i vrsta SIC-a mogu utjecati na rezultate, a to bi trebala biti tema daljnjih istraživanja. 
Although the antimicrobial properties of GIC tended to have a direct relationship with the concentration of zeolite, the amount of zeolite that GIC can successfully uptake is limited by its resulting mechanical properties. The change in shear bond strength of zeolite-incorporated GIC depended on the type and use of the GIC $(20,21)$. ZUT presented higher shear bond strength than GIC Ketac-Endo alone and was not affected when it was conditioned by media such as calcium hydroxide, chlorhexidine, formocresol, and deionized water (20). However, adding zeolite to provisional cements may decrease the shear bond strength between the dentin and composite resin. Zeolite provisional cement was compared against bone hydroxyapatite provisional cement and showed an inferior bonding strength. A possible explanation for the decrease is that zeolite-incorporated provisional cement may contain more calcium hydroxide than the bone hydroxyapatite-incorporated cement (21). The compressive strength of zeolite-GIC also had varying results depending on the type and use of zeolite $(13,16)$. Lee et al. reported that although AgZ GIC showed higher compressive strength at $1 \% \mathrm{wt}$, it decreased when the concentration was higher than $3 \%$ (13). However, Kim et al. concluded that there was no significant difference in compressive or bond strength when small amounts of chlorhexidine-loaded zeolite nanoparticles (around 1\% wt) were added to GIC (16).

\section{Resin Cements}

When zeolite was incorporated into resins, antimicrobial properties were improved against some microorganisms. Various ratios of AgZ and ZnZ inhibited S. mutans and S. mitis growth but did not inhibit $S$. salivarius or $S$. sanguis colonies. In contrast to what was observed with GIC, greater amounts of Ag-Zn-zeolite did not lead to greater amounts of antimicrobial activity in resins (3). After zeolite was modified with active diazonium, the compressive strength and flexural strength of the modified resin-based composite was either improved or remained the same (22). However, further research may be needed in this aspect of modifying zeolite because there is limited research on this topic.

\section{Bonding Agents}

Although zeolite alone did not improve the antimicrobial properties of bonding agents, the incorporation of $\mathrm{AgZ}$ did. Increasing the exchange time between $\mathrm{AgZ}$ and environmental ions can decrease biofilm formation of S. mutans, S. gordonii, and S. sanguinis on dental adhesives. Despite the linear relationship, increasing the amount of silver ions loaded into the zeolite so that the release time is greater than 40 minutes can result in damages to zeolite pore channels and uncontrollable silver ion release (23). Pretreating dentin with zinc zeolite may also enhance the shear bond strength between dentin and alloys using dental adhesives. This increase in shear bond strength was especially significant in the self-etch adhesive approach (24).

\section{Endodontics}

Zeolite in endodontics was generally added to calcium hydroxide and mineral trioxide aggregate (MTA) and used as root canal irrigants (25-31).
Iako su antimikrobna svojstva SIC-a bila u izravnom odnosu s koncentracijom zeolita, količina zeolita koju SIC može uspješno prihvatiti ograničena je mehaničkim svojstvima koja iz toga proizlaze. Promjena posmične čvrstoće veze SICa s ugrađenim zeolitom ovisila je o vrsti i upotrebi SIC-a (20, 21). ZUT je imao veću posmičnu čvrstoću od samoga SICa Ketac-Endo i nije bio pogođen medijima kao što su kalcijev hidroksid, klorheksidin, formokrezol i deionizirana voda (20). Međutim, dodavanje zeolita privremenim cementima može smanjiti posmičnu veznu čvrstoću između dentina i kompozitne smole. Privremeni cement sa zeolitom uspoređen je s privremenim cementom $s$ koštanim hidroksiapatitom i imao je manju veznu čvrstoću. Moguće objašnjenje za smanjenje jest da privremeni cement $s$ ugrađenim zeolitom može sadržavati više kalcijeva hidroksida od cementa s ugrađenim koštanim hidroksiapatitom (21). Za vlačnu čvrstoću SIC-a sa zeolitom također su dobiveni različiti rezultati, ovisno o vrsti i upotrebi zeolita $(13,16)$. Lee i suradnici izvijestili su da, iako je AgZ GIC imao veću tlačnu čvrstoću uz sadržaj od $1 \%$, ona se smanjila kada je koncentracija bila veća od $3 \%$ (13). No Kim i suradnici zaključili su da nema značajne razlike u tlačnoj ili veznoj čvrstoći kada su u SIC dodane male količine nanočestica zeolita napunjenih klorheksidinom (oko $1 \%$ ) (16).

\section{Kompozitni cementi}

Kada se zeolit ugradi u smole, poboljšana su antimikrobna svojstva protiv nekih mikroorganizama. Razni omjeri AgZ-a i ZnZ-a inhibiraju rast S. mutans i S. mitis, ali nisu inhibirali kolonije S. salivarius ili S. sanguis. Za razliku od onoga što je zapaženo kod SIC-a, veće količine Ag-Zn-zeolita nisu rezultirale boljim antimikrobnim djelovanjem u smolama (3). Nakon što je zeolit modificiran aktivnim diazonijem, tlačna i savojna čvrstoća preinačenoga kompozita na bazi smole ili su poboljšane ili su ostale iste (22). No o tom aspektu modificiranja zeolita potrebna su daljnja istraživanja jer su dosadašnja o toj temi ograničena.

\section{Adhezivi}

Iako sam zeolit nije poboljšao antimikrobna svojstva adheziva, ugradnja AgZ-a jest. Povećanje vremena razmjene između AgZ-a i iona iz okoline može smanjiti stvaranje biofilma S. mutans, S. gordonii i $S$. sanguinis na dentalnim adhezivima. Unatoč linearnom odnosu, povećanje količine srebrovih iona u zeolitu tako da vrijeme oslobađanja traje dulje od 40 minuta može rezultirati oštećenjima kanala pora zeolita i nekontroliranim oslobađanjem srebrnih iona (23). Prethodna obrada dentina cinkovim zeolitom također može poboljšati posmičnu veznu čvrstoću između dentina i legura primjenom dentalnih adheziva. To povećanje posmične vezne čvrstoće bilo je posebno značajno kod samojetkajućih adheziva (24).

\section{Endodoncija}

Zeolit u endodonciji općenito se dodaje kalcijevu hidroksidu i mineralnom trioksidnom agregatu (MTA) te se upotrebljava kao irigans korijenskoga kanala $(25-31)$. 


\section{Root Canal Irrigants}

Although 2\% AgZ did show statistically significant antimicrobial effectiveness as a root canal irrigant compared to the saline control, it did not exhibit as much effectiveness compared to common root canal irrigants such as 5\% Sodium hypochlorite, $2 \%$ Chlorhexidine, and $0.10 \%$ Octenidine (OCT) (25). A possible reason why AgZ was not as effective as the other root canal irrigants against $E$. faecalis, $C$. albicans, and $S$. aureus growth is that it was not as effective at breaking down the biofilm of these microorganisms (25). When further studies on the mechanical properties of $\mathrm{AgZ}$ are published, a better conclusion can be drawn on whether it is worth using $\mathrm{AgZ}$ as a root canal irrigant.

\section{Calcium hydroxide}

Calcium hydroxide is considered an ideal intracanal medication in endodontics due to its unique ability to increase surrounding $\mathrm{pH}$ by dissociating in water to produce hydroxyl ions. Although the high $\mathrm{pH}$ denatures bacterial protein and breaks down cell walls, calcium hydroxide was not effective on all types of microorganisms that cause endodontic infections. Ghatole et al. showed that when $\mathrm{AgZ}$ was added to calcium hydroxide, antimicrobial property against $E$. faecalis is enhanced compared to the control or when chlorhexidine is added (26). Therefore, AgZ can potentially be added to intracanal medications, such as calcium hydroxide, to improve antimicrobial effectiveness.

\section{MTA}

When $\mathrm{AgZ}$ was added to MTA, it exhibited significant antimicrobial properties toward selected oral microflora. $\mathrm{AgZ}$ in MTA was effective against most oral microorganisms, such as E. faecalis, S. aureus, and C. albicans. However, it was not effective against $P$. intermedia and $A$. israelii (27-28). No big differences were found in the types of microbes inhibited by $0.2 \%$ and $2 \%$ AgZ MTA, but $2 \%$ AgZ MTA demonstrated significantly higher inhibitory effects than $0.2 \%$ AgZ MTA throughout a 72-hour period. Specifically, 2\% AgZ demonstrated the highest amount of silver ion release at 24 hours (27). In addition, $2 \% \mathrm{AgZ}$ was found to have greater antimicrobial properties compared to MTA with $2 \%$ chlorhexidine (28). Therefore, $2 \% \mathrm{AgZ}$ could serve as a potential additive in MTA to enhance its antimicrobial properties.

Although zeolite significantly increased the antimicrobial properties of MTA, it did negatively affect physical properties such as setting time, water absorption, push-out bond strength and compressive strength (29-31). Setting time decreased as the ratio of $2 \% \mathrm{AgZ}$ increased, and water absorption was the lowest when $2 \% \mathrm{AgZ}$ was incorporated into MTA compared to the MTA-only control (29). In addition, adding $\mathrm{Ag}-\mathrm{Zn}-\mathrm{Ze}$ composite had a negative effect on the push-out bond strength and compressive strength of MTA (30-31). A possible reason for the decrease in push-out bond strength is that zeolite is very porous in its structure. When water molecules reside in the pores, they can disturb the hydration and crystallization processes of MTA (30). In conclusion, although zeolite may enhance the antimicrobial proper-

\section{Irigansi korijenskih kanala}

Iako je $2 \%$ AgZ-a imalo statistički značajnu antimikrobnu učinkovitost kao sredstvo za ispiranje korijenskih kanala u odnosu prema fiziološkoj otopini, nije pokazao toliku učinkovitost u usporedbi $s$ uobičajenim sredstvima za ispiranje kanala kao što su 5-postotni natrijev hipoklorit, 2-postotni klorheksidin i 0,10-postotni oktenidin (OKT) (25). Mogući razlog zašto AgZ nije bio toliko učinkovit kao druga sredstva za ispiranje korijenskoga kanala kad je riječ o rastu E. faecalis, C. albicans i $S$. aureus jest taj što nije bio toliko učinkovit u razgradnji biofilma tih mikroorganizama (25). Kada se objave daljnja istraživanja o mehaničkim svojstvima AgZ-a, moći se dati bolji zaključak o tome treba li upotrebljavati AgZ kao sredstvo za ispiranje korijenskog kanala.

\section{Kalcijev hidroksid}

Kalcijev hidroksid smatra se idealnim intrakanalnim lijekom u endodonciji zbog svojega jedinstvenog svojstva da poveća okolni $\mathrm{pH}$ razdvajanjem u vodi stvarajući hidroksilne ione. Iako visoki $\mathrm{pH}$ denaturira bakterijski protein i razbija stanične stijenke, kalcijev hidroksid nije učinkovito djelovao na sve vrste mikroorganizama koji uzrokuju endodontske infekcije. Ghatole i suradnici pokazali su da se dodavanjem AgZ-a kalcijevu hidroksidu pojačavaju antimikrobna svojstva protiv $E$. faecalis u usporedbi s kontrolom ili dodavanjem klorheksidina [26]. Zato se AgZ može dodati intrakanalnim lijekovima, kao što je kalcijev hidroksid, radi poboljšanja antimikrobne učinkovitosti.

\section{MTA}

Kad je AgZ dodan MTA-i, imao je izražena antimikrobna svojstva prema odabranim oralnim mikrobima. AgZ u MTAi učinkovito je djelovao na većinu oralnih mikroorganizama, kao što su E. faecalis, $S$. aureus i $C$. albicans. No nije bio učinkovit kad je riječ o P. intermedia i A. israelii [27 - 28]. Nisu pronađene velike razlike u vrstama mikroba koje su inhibirali $0,2 \%$ i $2 \%$ AgZ MTA-e, ali $2 \%$ AgZ MTA-e imao je značajno veći inhibitorni učinak od $0,2 \%$ AgZ MTA-e tijekom razdoblja od 72 sata. Točnije, $2 \% \mathrm{AgZ}$-a pokazalo je najveću količinu oslobađanja iona srebra u 24 sata (27). Uz to, utvrđeno je da $2 \%$ AgZ-a ima bolja antimikrobna svojstva u usporedbi s MTA-om s $2 \%$ klorheksidina (28). Zato bi 2 $\%$ AgZ-a moglo poslužiti kao aditiv u MTA-i za poboljšanje njezinih antimikrobnih svojstava.

Iako je zeolit značajno povećao antimikrobna svojstva MTA-e, negativno je utjecao na fizikalna svojstva kao što su vrijeme stvrdnjavanja, apsorpcija vode, vlačna i tlačna vezna čvrstoća $(29$ - 31). Vrijeme stvrdnjavanja smanjivalo se kako se povećavao omjer $2 \% \mathrm{AgZ}$-a, a apsorpcija vode bila je najmanja kada je $2 \%$ AgZ-a ugrađeno u MTA-u u usporedbi $s$ kontrolom gdje je bila samo MTA (29). Uz to, dodavanje kompozita Ag-Zn-Ze negativno je utjecalo na vlačnu i tlačnu veznu čvrstoću MTA-e $(30-31)$. Mogući razlog za smanjenje vezne čvrstoće jest taj što je struktura zeolita vrlo porozna. Kad se molekule vode nalaze u porama, mogu poremetiti procese hidratacije i kristalizacije MTA-e [30]. Zaključno, iako zeolit može pojačati antimikrobna svojstva MTA-e, on smanjuje mehanička svojstva. Zato su potrebna daljnja istra- 
ties of MTA, it does reduce the mechanical properties. Thus, further research is needed to determine the proper concentration of zeolite that may be incorporated into MTA, if any, to improve its antimicrobial properties without compromising its mechanical properties.

\section{Prosthesis}

Zeolite in prosthesis was added to both acrylic resin and non-acrylic materials, such as ceramic (32-38).

\section{Non-Acrylic Resins}

The non-acrylic materials that were tested with zeolite ranged from soft prosthetic liners to all-ceramic prosthesis. Adding $\mathrm{AgZ}$ to soft liners improved its antimicrobial properties against $C$. albicans and gram-negative bacteria while also retaining its viscoelastic properties (32). Regarding the mechanical properties, the applications of zeolite into ceramic prosthesis generally focused on sodalite zeolite (33-36), a subtype of zeolite that can easily infiltrate other material due to its selectivity and strong catalytic activity (33). In alumina and zirconium toughened alumina (ZTA) ceramic prostheses, sodalite zeolite-infiltrated samples had higher bond strength than the commercial glass-infiltrated samples between ceramic core and porcelain (34). In addition, all sodalite zeolite-infiltrated samples showed flexural strength above the acceptable ranges considered by the ISO (35-36). Furthermore, some studies have shown that the zeolite-infiltrated samples had a significantly higher flexural strength and hardness in comparison with glass-infiltrated control, especially when heated to $1600^{\circ} \mathrm{C}$ (35). Finally, sodalite zeoliteinfiltrated ZTA has one of the highest fracture toughness and elastic modulus values compared to its glass-infiltrated counterparts (33). Therefore, sodalite zeolite infiltrated samples can serve as a potential alternative to the glass infiltrated ZTA due to superior properties in bond strength, flexural strength, Vickers hardness, fracture toughness, and elastic modulus (33-36).

\section{Acrylic Resin}

$\mathrm{AgZ}$ increased the antimicrobial properties of acrylic resin against oral microbes such as $S$. mutans, F. nucleatum, and C. albicans. Self-cured acrylic resins tend to absorb copious amounts of water and do not easily polymerize, resulting in the accumulation of periodontal disease-causing bacteria. $\mathrm{AgZ}$-incorporated acrylic resin may potentially resolve this issue since it effectively diminished the attachment of $S$. mutans, F. nucleatum, and C. albicans to polymethylmethacrylate (PMMA) and lasted for up to 45-60 days (37-39). Similarly, 2.5\% Ag-Zn-Ze was effective at inhibiting C. albicans and S. mutans when added to PMMA (40). Therefore, both AgZ and $\mathrm{Ag}-\mathrm{Zn}$-Ze may be potentially viable options to improve the antimicrobial properties of PMMA.

However, depending on the percentage added, AgZ may negatively affect the mechanical properties of acrylic resin (38-41). Adding AgZ with concentrations of 2.5\% and higher, depending on the type of acrylic resin, will significantly reduce the impact and flexural strength $(38,40-41)$. However, some types of heat-cured acrylic resin, such as QC20 and Lucitone 550, may still satisfy the standard for denture živanja kako bi se utvrdila odgovarajuća koncentracija zeolita koji se može ugraditi u MTA-u, ako postoji, kako bi se poboljšala njegova antimikrobna svojstva, a da se pritom ne naruše ona mehanička.

\section{Protetika}

Zeolit u protezi dodaje se akrilatnoj smoli i neakrilatnim materijalima poput keramike $(32-38)$.

\section{Neakrilatne smole}

Neakrilatni materijali koji su ispitivani sa zeolitom kretali su se od materijala za mekano podlaganje proteza do potpuno keramičkih proteza. Dodavanjem AgZ-a materijalima za mekano podlaganje poboljšala su se njegova antimikrobna svojstva protiv C. albicans i gram-negativnih bakterija, a istodobno su se zadržala viskoelastična svojstva (32). Kad je riječ o mehaničkim svojstvima, primjena zeolita u keramičkim protezama uglavnom se fokusirala na sodalitni zeolit $(33-36)$, podvrstu zeolita koja se lako može infiltrirati u drugi materijal zbog selektivnosti i jake katalitičke aktivnosti (33). U keramičkim protezama od ojačane glinice i cirkonijeva oksida (ZTA), uzorci infiltrirani u zeolit sodalitom imali su veću veznu čvrstoću od komercijalnih uzoraka infiltriranih staklom između keramičke jezgre i obložne keramike (34). Uz to, svi uzorci infiltrirani zeolit sodalitom imali su savojnu čvrstoću iznad prihvatljivih granica prema ISO standardu (35 - 36). Nadalje, u nekim istraživanjima autori su pokazali da su uzorci infiltrirani zeolitom imali znatno veću savojnu čvrstoću i tvrdoću u usporedbi $s$ kontrolom infiltriranom staklom, posebno kada su zagrijani na $1600{ }^{\circ} \mathrm{C}(35)$. Konačno, ZTA sa zeolit sodalitom ima jednu od najvećih vrijednosti žilavosti i modula elastičnosti u usporedbi s materijalima infiltriranima staklom (33). Zato uzorci infiltrirani zeolit sodalitom mogu poslužiti kao potencijalna alternativa staklom infiltriranom ZTA-u zbog superiornih svojstava kad je riječ o veznoj i savojnoj čvrstoći, tvrdoći prema Vickersu, žilavosti i modulu elastičnosti $(33-36)$.

\section{Akrilatne smole}

$\mathrm{AgZ}$ je povećao antimikrobna svojstva akrilatnih smola kad je riječ o oralnim mikrobima kao što su $S$. mutans, $F$. nucleatum i C. albicans. Autopolimerizirajuće akrilatne smole imaju tendenciju upijanja obilnih količina vode i ne mogu se lako polimerizirati, što rezultira nakupljanjem parodontopatogenih bakterija. Akrilatna smola ugrađena u AgZ može riješiti taj problem jer učinkovito smanjuje vezanje $S$. mutans, F. nucleatum i C. albicans za polimetilmetakrilat (PMMA) u trajanju od 45 do 60 dana $(37-39)$. Slično tomu, $2,5 \% \mathrm{Ag}$ Zn-Ze-a bilo je učinkovito u inhibiciji C. albicans i $S$. mutans kada se doda u PMMA (40). Zato i AgZ i Ag-Zn-Ze mogu biti dobre opcije za poboljšanje antimikrobnih svojstava PMMA-e.

No ovisno o dodanom postotku, AgZ može negativno utjecati na mehanička svojstva akrilatne smole [38 - 41]. Dodavanje $\mathrm{AgZ}$-a u koncentracijama od 2,5\% i više, ovisno o vrsti akrilatne smole, značajno će smanjiti savojnu čvrstoću $(38,40-41)$. No neke vrste toplinski polimeriziranih akrilatnih smola, poput QC20 i Lucitone 550, još uvijek mogu zadovoljiti standard za akrilatne proteze koji zahtijeva savoj- 
acrylics, which requires flexural strength to be higher than $65 \mathrm{MPa}(38,40)$. Depending on the concentration of zeolite added, both mean tensile strength and bending strength decreased. It was recommended to add less than $4 \%$ zeolite wt to keep adequate mechanical strength, and $2 \%$ when factoring in both mechanical and fungicidal effects (39). Therefore, low percentages of silver-zinc antimicrobial zeolites added to polymethylmethacrylate can be a valuable alternative for antimicrobial effects, which could help prevent common oral infections such as denture stomatitis (38).

\section{Implants}

Numerous applications of zeolite also extend to antibacterial coatings on implants. Although there is not a great amount of literature on this topic, coating titanium implants with $\mathrm{AgZ}$ was effective in inhibiting methicillin-resistant $S$. aureus (MRSA) growth (42). This positive outcome, combined with zeolite's superior biocompatibility, may render zeolite a possible new material to be used in orthopedic implants.

\section{Limitations of the study}

Since most of the literature covered in the present review consisted of in vitro studies, it is important to note that there is a lack of widely accepted and clear criteria for assessing the risk of bias and quality of in vitro studies. To address this problem, a risk of bias test used in a previous study was adapted and used in this review (7). In the future, there should be more in vivo studies performed in order to better understand the effects of zeolite on the oral environment.

\section{Conclusion}

The available evidence collected through the present systematic review showed that ion-incorporated zeolite demonstrated enhanced antimicrobial properties when incorporated into dental materials. When ion-zeolite was incorporated into non-acrylic prosthetic materials, the mechanical as well as the antimicrobial properties were enhanced. GIC demonstrated the greatest antimicrobial effectiveness with $2 \%$ zeolite wt while maintaining mechanical properties between $1-3 \%$ zeolite wt. Therefore, it was recommended to use a concentration of $2 \%$ zeolite wt with GIC to optimize both factors. Lower concentrations such as $0.2-2 \%$ wt were recommended for MTA and acrylic prosthetic materials, which showed the greatest decrease in mechanical properties when combined with zeolite.

\section{Conflict of interest}

The authors report no conflict of interest.

\section{Acknowledgements}

The authors are grateful to Laurel Graham, Head of Penn Dental Medicine Library for guidance and organization for this systematic review.

This research did not receive any specific grant from funding agencies in the public, commercial, or not-for-profit sectors. nu čvrstoću veću od $65 \mathrm{MPa}(38,40)$. Ovisno o koncentraciji dodanoga zeolita, smanjile su se i srednja vlačna čvrstoća i savojna čvrstoća. Preporučeno je dodavanje manje od $4 \%$ zeolita kako bi se zadržala odgovarajuća mehanička svojstva, a $2 \%$ kada se uzimaju u obzir i mehanički i fungicidni učinak (39). Zato nizak postotak antimikrobnog srebrno-cinkova eolita dodanoga polimetilmetakrilatu može biti vrijedna alternativa za postizanje antimikrobnog učinka, što bi moglo pomoći u prevenciji uobičajenih oralnih infekcija poput protetičkog stomatitisa (38).

\section{Implantati}

Brojne primjene zeolita također se protežu na antibakterijske obloge na implantatima. Iako o toj temi nema mnogo radova, oblaganje titanijskih implantata AgZ-om učinkovito je inhibiralo rast bakterije $S$. aureus otporne na meticilin (MRSA) (42). Taj pozitivni ishod, u kombinaciji s vrhunskom biokompatibilnošću, zeolit može učiniti mogućim novim materijalom koji će se upotrebljavati u ortopedskim implantatima.

\section{Ograničenja istraživanja}

Budući da su većina radova obrađenih u ovom pregledu istraživanja in vitro, važno je napomenuti da nedostaju široko prihvaćeni i jasni kriteriji za procjenu rizika od pristranosti i kvalitete istraživanja in vitro. Kako bi se riješio taj problem, u ovom je pregledu prilagođen i korišten test rizika od pristranosti iz prethodnoga istraživanja (7). U budućnosti bi trebalo provesti više istraživanja in vivo da bi se bolje shvatili učinci zeolita u intraoralnom okružju.

\section{Zaključak}

Dokazi prikupljeni u ovomu sistematiziranom pregledu pokazali su da zeolit $s$ ugrađenim ionima ima pojačana antimikrobna svojstva kada se uključuje u dentalne materijale. Kada se zeolit $s$ ugrađenim ionima inkorporira u protetičke materijale koji nisu na bazi akrilata, poboljšana su mehanička i antimikrobna svojstva. SIC je imao najveću antimikrobnu učinkovitost s $2 \%$ masenoga udjela zeolita, zadržavajući mehanička svojstva između 1 i $3 \%$ udjela zeolita. Zato je preporučena koncentracija od $2 \%$ zeolita u SIC-u za optimizaciju obaju čimbenika. Niže koncentracije poput 0,2 do $2 \%$ preporučene su za MTA i akrilatne protetičke materijale koji su pokazali najveće narušavanje mehaničkih svojstava u kombinaciji sa zeolitom.

\section{Sukob interesa}

Autori ne navode sukob interesa.

\section{Zahvala}

Autori zahvaljuju Laurel Graham, voditeljici Penn Dental Medicine Library za smjernice i organizaciju ovoga sistematiziranog pregleda.

Ovo istraživanje nije dobilo nikakvu potporu agencija za financiranje u javnom, komercijalnom ili neprofitnom sektoru. 
Author's contribution: J.H. - Collecting, organizing and validating data, Software applications for data analysis, Original draft paper prep aration and writing; S.L. - Planning, organizing and validating data, Helping with software designs, Original draft paper preparation and writing; F.M. - Statistical calculations, Data analysis and interpretation, Reviewing and editing the article; K.P. - Consulting, reviewing and editing the article; F.O. - Design and supervision of the study project, Funding acquisition, Critical revision of the article, Final approval of the version to be published.
Doprinos autora: J.H. - prikupljanje, organiziranje i provjeravanje podataka, softverske aplikacije za analizu podataka, priprema i pisanje izvornog članka; S.L. - planiranje, organiziranje i provjeravanje podataka, pomoć u dizajniranju softvera, priprema i pisanje izvornog članka; F.M. - Statistički izračuni, analiza i interpretacija podataka, pregled i uređivanje članka; K.P. - savjetovanje, pregled i uređivanje članka; F.O. - Dizajn i nadzor studijskog projekta, prikupljanje financijskih sredstava, kritična revizija članka, konačno odobrenje verzije koja će se objaviti.

\section{Sažetak}

Svrha istraživanja: Zeolit s ugrađenim ionima često je korišten antimikrobni materijal koji se proučava za različite primjene u stomatologiji. Trenutačno ne postoji ni jedan drugi sistematizirani pregledni rad u kojemu bi se ocjenjivala učinkovitost zeolita u svim dentalnim materijalima. Svrha ovoga istraživanja bila je pregledati svu objavljenu literaturu u kojoj su analizirani antimikrobni učinci i/ ili mehanička svojstva zeolita kao restaurativnog materijala u stomatologiji. Materijal i metode: Slijedeći smjernice PRISMA-e, od 1. lipnja do 17. kolovoza 2020. provedeno je iscrpno pretraživanje baza Pubmed, Ovid Medline, Scopus, Embasa te Dentistry i Oral Sciences Source. Nisu korištena jezična ili vremenska ograničenja. Odabrani su samo cjeloviti članci kojima je tema bila upotreba zeolita u dentalnim materijalima, uključujući kompozitne materijale, adhezive, cemente, restaurativne intrakorijenske materijale, podloge te materijale u protetici, implantologiji i endodonciji. Rezultati: Na početku su pronađena 1534 istraživanja, od kojih je isključeno 687 duplih zapisa. Nakon pregleda naslova, sažetka i cjelovitih tekstova, ostalo je 35 radova koji su uključeni u kvalitativnu sintezu. Za svaki od njih proveden je test pouzdanosti među ocjenjivačima (IRR) koji je obuhvaćao postotak slaganja i postotak pouzdanosti. Zaključak: lako zeolit s ugrađenim ionima može pojačati antimikrobna svojstva dentalnih materijala, mehanička svojstva nekih mogu biti ugrožena, poput MTA i akrilatne smole. Stoga, s obzirom na to da pogoršanje mehaničkih svojstava ovisi o koncentraciji zeolita u restaurativnom materijalu, općenito se preporučuje dodavanje 0,2 do 2 mas.\% zeolita.
Zaprimljen: 8. studeni 2020. Prihvaćen: 1. veljače 2021.

Adresa za dopisivanje

Fusun Ozer, DMD, PhD

University of Pennsylvania,

School of Dental Medicine

Department of Preventive and

Restorative Sciences,

240 S 40th Street, Schattner Building,

Philadelphia, PA 19106, USA

tel: +1 2155733751

ozerf@upenn.edu

MeSH pojmovi: zeoliti; mehanički fenomeni; antimikrobna sredstva; stomatološki materijali

Ključne riječi: zeolit, dentalni materijali, antimikrobno, mehanička svojstva, sistematizirani pregledni rad

\section{References}

1. Pavelić S, Medica J, Gumbarević D, Filošević A, Przulj N, Pavelić K. Critical review on zeolite clinoptilolite safety and medical applications in vivo. Front Pharmacol. 2018 Nov 27;9:1350.

2. Derakhshankhah H, Jafari S, Sarvari S, Barzegari E, Moakedi F, Ghorbani M, et al. Biomedical applications of zeolitic nanoparticles, with an emphasis on medical interventions. Int J Nanomedicine. 2020 Jan 21;15:363-386.

3. Hotta M, Nakajima H, Yamamoto K, Aono M. Antibacterial temporary filling materials: the effect of adding various ratios of $\mathrm{Ag}-\mathrm{Zn}$ Zeolite. J Oral Rehabil. 1998 Jul;25(7):485-9.

4. Kawahara K, Tsuruda K, Morishita M, Uchida M. Antibacterial effect of silver-zeolite on oral bacteria under anaerobic conditions. Dent Mater. 2000 Nov;16(6):452-5.

5. Sivakumar I, Arunachalam K, Sajjan S, Ramaraju A, Rao B, Kamaraj B. Incorporation of antimicrobial macromolecules in acrylic denture base resins: a research composition and update. J Prosthodont. 2014 Jun;23(4):284-90.

6. Wang L, D’Alpino P, Lopes L, Pereira J. Mechanical properties of dental restorative materials: relative contribution of laboratory tests. Journal of Applied Oral Science. 2003; 11:162-167.

7. Astudillo-Rubio D, Delgado-Gaete A, Bellot-Arcís C, Montiel-Company J, Pascual-Moscardó A, Almerich-Silla J. Mechanical properties of provisional dental materials: a systematic review and meta-analysis. PLoS One. 2018 Feb 28;13(2):e0193162.

8. McHugh ML. Interrater reliability: the kappa statistic. Biochemia medica. 2012; 22(3): 276-282.

9. Moher D, Liberati A, Tetzlaff J, Altman DG. The PRISMA Group, Preferred reporting items for systematic reviews and meta-analyses: the PRISMA statement. PLoS Medicine. 2009; 6(7): e1000097.

10. Saengmee-anupharb S, Srikhirin T, Thaweboon B, Thaweboon S, Amornsakchai T, Dechkunakorn S, Suddhasthira T. Antimicrobial effects of silver zeolite, silver zirconium phosphate silicate and silver zirconium phosphate against oral microorganisms. Asian Pac J Trop Biomed. 2013 Jan;3(1):47-52.

11. Partoazar A, Talaei N, Bahador A, Pourhajibagher M, Dehpour S, Sadati M, Bakhtiarian A. Antibiofilm activity of natural zeolite supported NanoZnO: inhibition of Esp gene expression of Enterococcus faecalis. Nanomedicine (Lond). 2019 Mar;14(6):675-687.

12. Tamanai-Shacoori Z, Chandad F, Rébillard A, Cillard J, Bonnaure Mallet M. Silver-zeolite combined to polyphenol-rich extracts of ascophyllum nodosum potential active role in prevention of periodontal diseases. PLoS One. 2014 Oct 1;9(10):e105475.

13. Lee JH, Lee S, Kim KN, Kim KM, Lee YK. Antibacterial effect of silver-zeolites in glass-ionomer cements. J Biomed Mater Res B Appl Biomater. 2009 Aug;90(2):592-5.

14. Cinar C, Ulusu T, Ozçelik B, Karamüftüoğlu N, Yücel H. Antibacterial effect of silver-zeolite containing root-canal filling material. Journal of Biomedical Materials Research, Part B Applied Biomaterials. 2009;90(2):592-595.

15. Mabrouk M, Selim M, Beherei HH, El Gohary MI. Incorporation effect of silver and zinc-zeolites into commercial glass ionomer cement. International Ceramic Review. 2013;62(1):50-54.

16. Kim HJ, Son JS, Kim KH, Kwon TY. Antimicrobial activity of glass ionomer cement incorporated with chlorhexidine-loaded zeolite nanoparticles. Journal of Nanoscience and Nanotechnology. 2016;16(2):1450-1453.

17. Patel V, Santerre JP, Friedman S. Suppression of bacterial ad herence by experimental root canal sealers. J Endod. 2000 Jan;26(1):20-4

18. Padachey N, Patel V, Santerre P, Cvitkovitch D, Lawrence HP, Friedman S. Resistance of a novel root canal sealer to bacterial ingress in vitro. J Endod. 2000 Nov;26(11):656-9.

19. McDougall I, Patel V, Santerre P, Friedman S. Resistance of experimental glass ionomer cement sealers to bacterial penetration in vitro, Journal of Endodontics. 1999;25(11): 739-742.

20. Chung HA, Titley K, Torneck CD, Lawrence HP, Friedman S. Ad hesion of glass-ionomer cement sealers to bovine dentin conditioned with intracanal medications. Journal of Endodontics. 2001;27(2):85-88.

21. Can-Karabulut D, Akincioğlu A, Özyeğin S, Karabulut B. Influence of experimental provisional cements containing zeolite, bone hydroxyapatite and linoleic acid on bond strength of composite to dentin in vitro. J Adhes Dent. 2010 Dec;12(6):469-75.

22. Sandomierski M, Okulus Z, Voelkel A. Active diazonium-modified zeolite fillers for methacrylate-based composites. Composite Interfaces. 2019;26(7):643-657.

23. Li W, Qi M, Sun X, Chi M, Wan Y, Zheng X, Li C, Wang L, Dong B. Novel dental adhesive containing silver exchanged EMT zeolites against cariogenic biofilms to combat dental caries. Microporous and Mesoporous Materials. 2020;299:110113. 
24. El-Guindy J, Selim M, El-Agroudi M. Alternative pretreatment modalities with a self-adhesive system to promote dentin/alloy shear bond strength. J Prosthodont. 2010 Apr;19(3):205-11.

25. Ghivari S, Bhattacharya H, Bhat K, Pujar M. Antimicrobial activity of root canal irrigants against biofilm forming pathogens- An in vitro study. J Conserv Dent. May-Jun 2017;20(3):147-151.

26. Ghatole K, Gowdra R, Azher S, S. Sabharwal S. Enhancing the an tibacterial activity of the gold standard intracanal medicament with incorporation of silver zeolite: An in vitro study. J Int Soc Prev Community Dent. Jan-Feb 2016;6(1):75-9.

27. Odabaş M, Çinar Ç, Akça G, Araz I, Ulusu T, Yücel H. Short-term antimicrobial properties of mineral trioxide aggregate with incorporated silver-zeolite. Dent Traumatol. 2011 Jun;27(3):189-94.

28. Ghatole K, Patel A, Giriyappa R, Singh T, Jyotsna S, Rairam S. Evaluation of antibacterial efficacy of MTA with and without additives like silver zeolite and chlorhexidine. J Clin Diagn Res. 2016 Jun;10(6):ZC11-4

29. Çinar Ç, Odabaş M, Gürel M, Baldağ I. The effects of incorporation of silver-zeolite on selected properties of mineral trioxide aggregate. Dent Mater J. 2013;32(6):872-6.

30. N. Ghasemi N, S. Rahimi S, M. Samiei M, M. Mohamadi M, Y. Rezaei Y, B. Divband B, N. Farhangi N. Effect of zeolite containing silver-zinc nanoparticles on the push out bond strength of mineral trioxide aggregate in simulated furcation perforation. J Dent (Shiraz). 2019 Jun;20(2):102-106.

31. Samiei M, Ghasemi N, Asl-Aminabadi N, Divband B, GolparvarDashti Y, Shirazi S. Zeolite-silver-zinc nanoparticles: Biocompatibility and their effect on the compressive strength of mineral trioxide aggregate. J Clin Exp Dent. 2017 Mar 1;9(3):e356-e360.

32. Saravanan M, Kumar V, Padmanabhan T, Banu F. Viscoelastic properties and antimicrobial effects of soft liners with silver zeolite in complete dental prosthesis wearers: an in vivo study. Int J Prosthodont. May-Jun 2015;28(3):265-9.

33. Naji G, Omar R, Yahya R. The effect of sodalite zeolite infiltrated material on the fracture toughness, elastic modulus and op- tical properties of all-ceramic dental prostheses. Ceram Int 2016;42(16):18737-18746.

34. Naji G, Omar R, Yahya R. Influence of sodalite zeolite infiltration on the coefficient of thermal expansion and bond strength of allceramic dental prostheses. J Mech Behav Biomed Mater. 2017 Mar;67:135-143.

35. Naji G, Omar R, Dabbagh A, Yahya R. Effect of sintering temperature on the microstructures and mechanical properties of sodalite infiltrate all-ceramic material for dental restorations. Adv Appl Ceram. 2018;117(5):291-302.

36. Naji G, Omar R, Yahya R, Dabbagh A. Sodalite zeolite as an alternative all-ceramic infiltrating material for alumina and zirconia toughened alumina frameworks. Ceram Int. 42;(10):1225312261.

37. Kuroki K, Hayashi T, Sato K, Asai T, Okano M, Kominami Y, et al. Effect of self-cured acrylic resin added with an inorganic antibacterial agent on Streptococcus mutans. Dent Mater J. 2010 May;29(3):277-85.

38. Malic S, Rai S, Redfern J, Pritchett J, Liauw C, Verran J, Tosheva L. Zeolite-embedded silver extends antimicrobial activity of dental acrylics. Colloids Surf B Biointerfaces. 2019 Jan 1;173:52-57.

39. Nakanoda S, Nikawa H, Hamada T, Yamamoto T, Nakamoto K. The material and antifungal properties of antibiotic zeolite incorporated acrylic resin. Japanese Prosthodontic Society. 1995;39(5):919926

40. Casemiro L, Martins C, Pires de Sousa F, Panzeri H. Antimicrobial and mechanical properties of acrylic resins with incorporated silver-zinc zeolite - part I. Gerodontology. 2008 Sep;25(3):187-94.

41. Yadav N, Saraf S, Mishra S, Hazari P. Effects of fluconazole, chlorhexidine gluconate, and silver-zinc zeolite on flexural strength of heat-cured polymethyl methacrylate resin. J Nat Sci Biol Med. Jul-Dec 2015;6(2):340-2.

42. Wang J, Wang Z, Guo S, Zhang J, Song Y, Dong X, Wang X, Yu J. Antibacterial and anti-adhesive zeolite coatings on titanium alloy surface. Micropor Mesopor Mat. 2011; 146(1):216-222. 